\title{
Application of Robotics UV-light Device In Averting The Spread of Coronavirus.
}

\section{Damian Benneth Nwoye Nnadi}

University of Nigeria Faculty of Engineering

Timothy Oluwaseun Araoye ( $\boldsymbol{\nabla}$ timothy.araoye@unn.edu.ng )

University of Nigeria Faculty of Engineering https://orcid.org/0000-0002-8405-465X

\section{Sochima Vincent Egoigwe}

University of Nigeria Faculty of Engineering

Deborah Ahuoiza Vincent

University of Nigeria

\section{Research Article}

Keywords: Coronavirus pandemic, ultra-violet light, Electromagnetic light, Robotic, SARS-CoV-2, sanitizer

Posted Date: June 21st, 2021

DOI: https://doi.org/10.21203/rs.3.rs-568749/v1

License: (c) (1) This work is licensed under a Creative Commons Attribution 4.0 International License.

Read Full License 
2 Damian Benneth Nwoye Nnadi ${ }^{1}$, Timothy Oluwaseun Araoye ${ }^{2}$, Sochima Vincent Egoigwe ${ }^{3}$ and Deborah

3 Ahuoiza Vincent ${ }^{4}$

$4 \quad{ }^{1}$ Department of Electrical Engineering, University of Nigeria, Nsukka, Nigeria

$5 \quad{ }^{2,3}$ Department of Mechatronics Engineering, University of Nigeria, Nsukka, Nigeria

$6 \quad{ }^{4}$ Department of Industrial Technical Education, University of Nigeria, Nsukka, Nigeria

Corresponding Name: Timothy Oluwaseun Araoye

Corresponding email: timothy.araoye@unn.edu.ng

10

11

\begin{abstract}
This research focused on robotic ultraviolet light (RUV light) for sanitizing the environment due to the outbreak of the Coronavirus pandemic devastating the whole world. The prototype Robotics UV-light device was proposed in this research to relieve mankind of sanitization of the ecosystem since SARS-CoV-II is highly infectious. The robotic Ultra-violet system was developed using perception subsystems as well as cognition subsystems, all linked together to perform the needed functions. Nine perceptions recognition subsystems were deployed with a remote controller for the driving as well as monitoring of the system for optimum performance while in operation. The Robotics was built with four lamps of ultra-violet lights such that while in operation, the targeted environment gets sanitized at the same time. An extra lamp was attached at the top end of the robotic device which is used to fumigate the upper part of the wards where the other lights could not reach. One of the inbuilt perception subsystems collects information on the extent of sanitization and then via the cognition subsystem shuts down the system automatically. If by chance a novice approaches the ward(s) where the robotic system is working, another perception subsystem will perceive human presences and through the cognitive device raises a mimic human tone programmed, "this place is not safe now, quickly shift". If within ten nanoseconds and the novice still resist the warning, then the machine shutdown automatically. The performance of this electromagnetic light has an efficiency of 99.99 percent over both bacteria and viruses including Covid-19.
\end{abstract}

Keywords: Coronavirus pandemic, ultra-violet light, Electromagnetic light, Robotic, SARS-CoV-2, sanitizer.

\section{Introduction:}

The world over is witnessing another serious pandemic since the last H1N1 virus pandemic in the year 1918 followed by H2N2 pandemic of 1957-1958. This recent pandemic called covid-19 by World Health Organization on March $11^{\text {th }}, 2020$, raised its ugly head in Wuhan Laboratory China by December 2019, though it has not spread to other places. At the onset of the outbreak WHO and other scientists gave the pandemic an interim name as 2019-nCoV (Laboratory testing of coronavirus, 2020)(Novel Coronavirus, 2019)(Novel Coronavirus, 2020). It was later that organization called the International Committee on Taxonomy of Virus renamed the pandemic as SARS-CoV-II. On further research was done by (World health organization 2019), the research came to terms with earlier researchers that the virus is a respiratory disease activated by unembellished acute respiratory syndrome coronavirus II, hence, in support of the name SARS-CoV-II. The infectiousness of COVID-19 ranges from mild with no symptom(s) to severe ailment that may lead to the death of its victim. The symptoms seen with severe COVID-19 patients range from high fever, general body weakness, acute cough to a sore throat. Other signs include headaches and body pains, a state of anosmia, ageusia as well as vitiligo, diarrhea and finally may lead to dyspnea. To checkmate the blowout of the disease which spread like a wildfire, several efforts from different health specialists were made but to no avail. Many unlucky persons still fall under the cold hands of that wicked disease. Funny enough the disease is a respecter of no man, neither color, race, age nor social status; it only the immunity level in its victim does it respect. All activities ongoing previously in the world were brought to a standstill instantly; be it social, economic, or even global activities. To that effect, many nation's economies both giants and weaklings were capsized.

As in the case of most contagious diseases, the transmissibility of SARS-CoV-II - the beta version of coronavirus that caused COVID-19 happened by one-on-one interaction with the carrier or any object touched by the carrier and also by airborne routes. Hence, from research, SARS-CoV-2 was been destroyed or destabilized by aerosols within a short span of at least 3hours (Van et al, 2020). The news of the high rate of mortalities as a result of Covid-19, all hands were on deck to combat the nemeses ravaging the world over. So many measures were adopted to minimize the wild spread, some of such measures were, use of liquid disinfectants either to wash hands or just to spray in the hands, masking of mouth and nose, staying 6 feet apart 
in any public gatherings including other personal hygiene practices. On the other hand, some drugs were recommended for anybody that contacts the deadly disease. Such drugs include Paracetamol tablets, Vitamin C natural or synthesized $\mathrm{D}_{3}$, and $\mathrm{B}$ complex natural or synthesized, Vapor or capsules for the stream, hydroxychloroquine tablets or chloroquine tablets, and dexamethasone. Other devices recommended for the intensive care unit (ICU) were Oximeter, oxygen cylinder, and breathing exercise. In addition to the sanitary measures, social distancing, Moez Guettari, (2020) advocated for environmental fumigation, thorough testing of individuals, and quarantine of any alleged person for two weeks. Furthermore, two genetically engineered antibody from a single clone were made available for treatments (Bamlanivimab, was a product from Eli Lilly; with a combination of Casirivimab and Imdevimab, manufactured by Regeneron company) were given emergency endorsement for use by the American Food and Drug Administration (FDA) in November 2020.

In the event of environmental disinfection, Otto et al, (2011), mojarad et al, (2017) and Darnella el al, (2004) classified the cleansing procedures into chemical and physical types. According to references above ecological factors like temperature if $\geq 65^{\circ} \mathrm{C}$ deactivates the virus. It was also observed that alkalinity $(p H>$ 12) or acidity $(\mathrm{pH}<3)$ incapacitates the virus. Other factors to be considered for effective fumigation were the quantity of calcium and magnesium dissolved in water, the quantity of soluble and particulate organic matter, topographical space, other chemical compounds available in the liquid indicates the decontamination tactics to adopt. Moez Guettari, (2020), opined that chemical decontamination tactics contain some reagents grouped based on their nature: (1) acidic nature: acetic acid and citric acid; (2) alcoholic nature: $\mathrm{C}_{2} \mathrm{H}_{6} \mathrm{O}$ or $\mathrm{CH}_{3} \mathrm{CH}_{2} \mathrm{OH}$ and $\mathrm{C} 3 \mathrm{H} 8 \mathrm{O}$ or $\mathrm{CH} 3 \mathrm{CHOHC}$; (3) aldehydic nature: formaldehyde and gluteraldehyde; (4) alkalic nature: $\mathrm{NaOH}$ or $\mathrm{AI}(\mathrm{OH})_{2}, \mathrm{Na}_{2} \mathrm{CO}_{3}$, and $\mathrm{Ca}(\mathrm{OH})$; (5) biguanides nature: chlorhexidine; (6) halogenic nature: $\mathrm{Cl}$ or $\mathrm{I}_{2}$ composites; (7) oxidizing agents; and (8) quaternary ammonium compounds.

Of recent, many companies have produced vaccines in curtailing the wild spread of the virus, though not yet accepted by many people. Debates are still ongoing as regards the vaccines' effectiveness and efficacy. Hence, this project was conceived to investigate the effectiveness of ultra-violet light in curbing this dreaded virus. Bai et al (2020) opined that since the pandemic is a more or less airborne virus a more pragmatic approach is adopted in pursuit of it. Hence, this research then adopted spraying ultra-violet light by machine, thereby minimizing the spread. Six species of human coronaviruses were in existence from literature, though a species mutated to give additional new strain. As opined by some academicians that four of the six human coronaviruses have mild symptoms, though still under dispute (King and Anthony, 1971). Such species of human coronaviruses include (King and Anthony, 1971) OC43 ( $\mathrm{HCoV}-\mathrm{OC} 43$ ) called $\beta-\mathrm{CoV}$, human coronavirus type HKU1 (HCoV-HKU1) or is called $\beta-\mathrm{CoV}$. Another human coronavirus species is $229 \mathrm{E}$ (HCoV-229E also called $\alpha-\mathrm{CoV}$, the last of them all is human coronavirus NL63 (HCoV-63) called $\alpha-\mathrm{CoV}$. Some possibly severe symptoms that three human coronaviruses produce were "mid-east respiratory syndrome-related coronavirus" known as (MERS-CoV) or $\beta-\mathrm{CoV}$, severe acute respiratory syndrome-related coronavirus called (SARS-CoV) or $\beta-\mathrm{CoV}$, severe acute respiratory syndrome coronavirus II (SARS-CoV-II) or $\beta-\mathrm{CoV}$.

Even though several regulatory procedures had been put in place, yet the virus continued to spread like a wildfire unabated. This reason gave the research the impetus to look into robotic UV light as a means of averting the menacing of this pandemic. The light from electromagnetic waves can efficaciously neutralize microbes or viruses in the air that spread SARS COV-1. It is on record that sickness like measles, tuberculosis, eczema, acne, and psoriasis, etc., were been caused by some of these microbes like bacteria, fungi, pathogens, parasites, viruses, spores, dust mite, which for some decades ago, UV-light has been proved to have reduced the spread of them. Therefore, UV-light efficacy needed to be appraised in the deactivating of Covid-19 growth. UV radiation has been adopted in some healthcare units to sanitize surfaces, objects, water, air, and sterilize microorganisms. There are different wavelengths of radiation, UV-light which has much energy, and smaller wavelength when compared with radio waves or visible light. On the contrary, either X-radiation or $\gamma$-rays have more energy than UV-light. The spectrum of UV-light showed its three regions - the near-ultraviolet (NUV)closest to optical light and is visible to some insects, birds, dogs, etc., the far-ultraviolet (FUV) has 122-200 nanometer, and the extreme ultraviolet (EUV) 10 - 124 nanometer. Man can receive UV light naturally using sunlight or via a man-made device like tanning beds. Lucas (2017) discussed UV-light as electromagnetic radiation, capable of terminating the microbes at the formation stage thereby thwarting its procreation. The scholar further stressed that the origin of the radiation was from the sun, though conveyed as waves at various wavelengths and frequencies. Other sources can generate UV-light other than the sun, fluorescent and 
incandescent bulbs, mercury vapor light, halogen light, lasers, discharge lamps, etc. UV-light was further classified by Derraik et al, (2020) into three types namely, ultraviolet A (UVA) having wavelengths of 320400nm, ultraviolet B (UVB)- 280 - 320 nanometer, and ultraviolet C (UVC) - 200 - 280 nanometers. UV-light according to Hebling et al (2020) could be utilized in sanitizing ecosystems and their environs due to its sensitive nature. Then the actions of the light thereby mitigate the spread of coronaviruses. Referring to Figure 1, (ASHRAE 2019)(UVC LED Disinfection 2013) showcased that smaller wavelengths of UVC not only incapacitate viruses, bacteria, and fungi but also make them un-procreative or even cause sickness.

The efficacy of UV-light was further confirmed by Kowalski (2009) which shows the ability to destroy fungi, bacteria, and viruses in hundreds of laboratory studies. Another scholar showed the vulnerability of SARS-CoV2 to UV-light, the virus showed high weakness when exposed to UV-light (Heilingloh et al, 2020). The observation of Narita et al, (2018) from Figure 2 revealed that ultraviolet light within the wavelength range of 207 - 222 nanometers is highly effective in conventional germicidal ultraviolet light employed in destroying microbes.

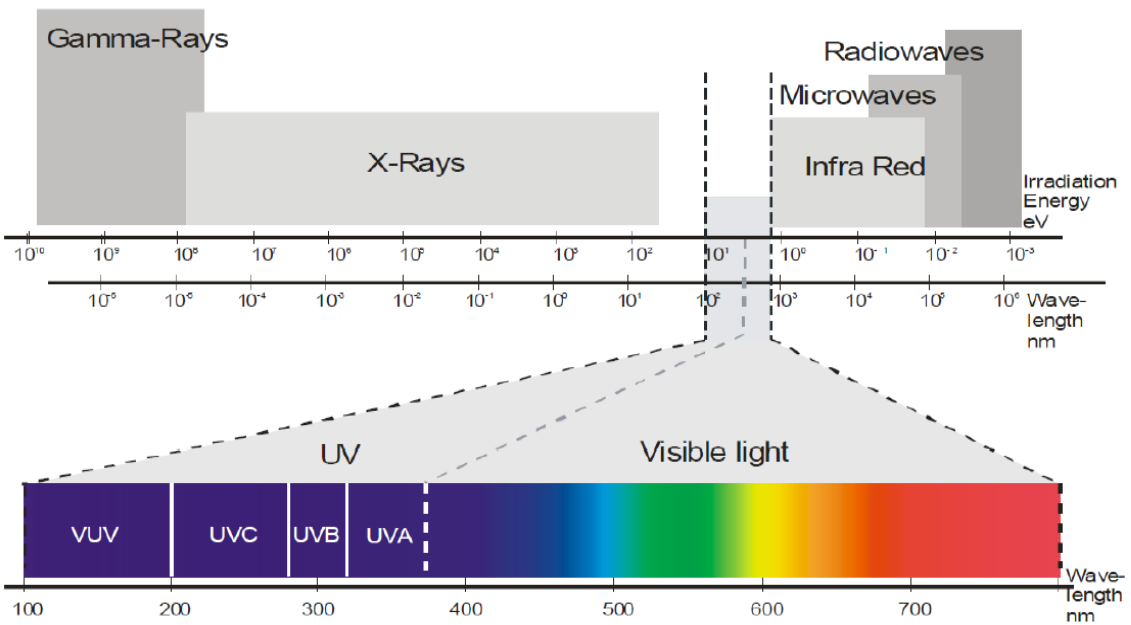

Figure 1: Electromagnetic Spectrum (UVC LED Disinfection, 2013)

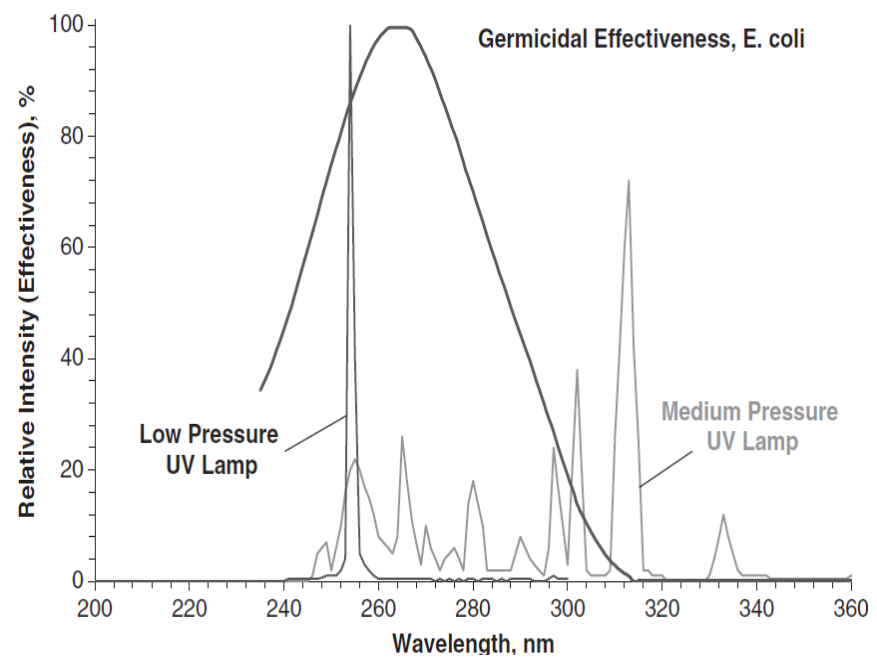

Figure 2: Comparison of germicidal efficiency ultraviolet wavelengths of much (or average) and lower-pressure ultra-violet lamps with germicidal effectiveness for E. coli, (Luckiesh 1946)(IESNA, 2000).

Of course, Kitagawa et al (2020) discovered that ultraviolet light of wavelength 222 nanometer, even though safe for human life but it still deactivates coronaviruses. The researchers experimentally exposed the covid-19 virus to 222 nanometers UV-light at $0.1 \mathrm{Mw}$ per $\mathrm{cm}^{2}$ and observed that after 30 seconds viruses were all dead. Hence, the wavelength of UV light matters much in achieving the desired result. A contradictory result arose as some researchers showcased that ultraviolet B produced better results in deactivating viruses. 
Some inherent disadvantages of ultraviolet lights when exposed to include skin burn, skin cancer, more so it produces wrinkles on the body, age spots, eye burn, it is also capable of causing damages in genetics or DNA, hence resulting in a mutation in the victim(s) (Trevisan et al, 2006)(Zafna et al, 2012)(Setlow et al, 1993)(Balasubramanian et al, 2000).

The human risks involved in the use of UV-light do not affect its efficacies in the sanitization of environs, personal protective equipment (PPE), treatment of water, and as well as sterilization of medical equipment. Even though UV light has these advantages to its credit, caution should be employed while in use even though it is a good approach for microbes to be exposed to ultraviolet light (Kowalski, 2009), and also such exposures combat seriously with various strains of viruses thereby incapacitating them (Budowsky et al, 1981). Of recent xenon lamps which generate broad ultraviolet spectrum were now employed for germicidal Naunovic et al, (2008); but farhad et al (2010) claimed that for "scrubbing" health care environs, equipment and lab UV germicidal irradiation (UVGI) has been utilized for years now.

\section{The operational mechanism of the prototype ultra-violet robotic device,}

The prototype Robotic UV-light system was implemented using nine perception subsystems as well as cognition subsystems. The main element in the perception subsystem is the sensors. Six of the sensors were in charge of the robotic movement, where the other three remain performed different assignments for the effective performance of the device. One of the other three remaining perception subsystems monitors the degree of sanitization of the environs of which within 15-25 minutes the fumigation will be over. At this point, the cognition subsystem will then determine the next action to be taken by the robot. The second perception subsystem in conjunction with the cognition subsystem perceives human presence when the sanitization process is ongoing, a mimic human tone programmed, "this place is not safe now, quickly shift", will then be initialized. Waiting for 0.12 seconds and such individual respond not to the warning, the cognition subsystem then activates stoppage of the device on its own. The third perception subsystem with its counterpart in the cognition subsystem monitors ultraviolet at the upper/head of the robotic device for the sanitization of the upper part of the wards where the fumigation is taking place.

The UV light was designed to look like a lamp with a shining surface that reflects all the light intensity at an angle of $180^{\circ}$ frontwards. There are four of these lamps around the robotic device, which cover all the environs to fumigate. As soon as the robot system gets to its target place of work, through the remote controller, the device will be set to work making some movements appropriately. Then, the perception and cognition subsystems monitor as well as taking decisions determine the degree of fumigation takes appropriate action at the due time. Figure 3 depicted the prototype ultraviolet light system.

\section{UVC light models.}

In modeling of ultraviolet-light, Chick (1908) in his work gave the fundamental rate model of sanitization and the formula is as shown in Eq. (1)

$$
\frac{d \Xi}{d t}=-m \Xi
$$

where $\Xi$ is the number of the microbes at time $t(\mathrm{sec})$ and $\mathrm{m}$ is the rate of observed sanitization. Furthermore, following the work of Kamiko et al (1989), Eq. (1) is transformed to be Eq (2);

$$
\frac{d \Xi}{d t}=Y \zeta \Xi
$$

here $\zeta$ depicted the ultraviolet intensity measured in $\left(\mu \mathrm{W}\right.$ per $\left.\mathrm{cm}^{2}\right)$ and $\mathrm{Y}$ is the microbes vulnerability factor measured in $\left(\mathrm{cm}^{2} \mu^{-1} \mathrm{Ws}^{-1}\right)$. The vulnerability constraints fluctuate with ecological situations, such as atmospheric relative humidity (Ko et al, 2000)(Mcdevitt, 2012). From observation, ultraviolet C efficacy declines with growing atmospheric relative humidity (Mcdevitt, 2012).

The drive current of ultraviolet intensity, $\zeta\left(\mu \mathrm{W}\right.$ per $\mathrm{cm}^{2}$ ) was given in Eq. (3)

$$
\zeta=\left(\frac{\log _{e}\left(\frac{B_{262}^{0}}{B_{262}}\right)}{\tau}\right) \times\left(\frac{\aleph}{2.303 \times 1000 \times \exists_{262} \times \varphi}\right)\left(\mu \mathrm{W} \text { per } \mathrm{cm}^{2}\right)
$$




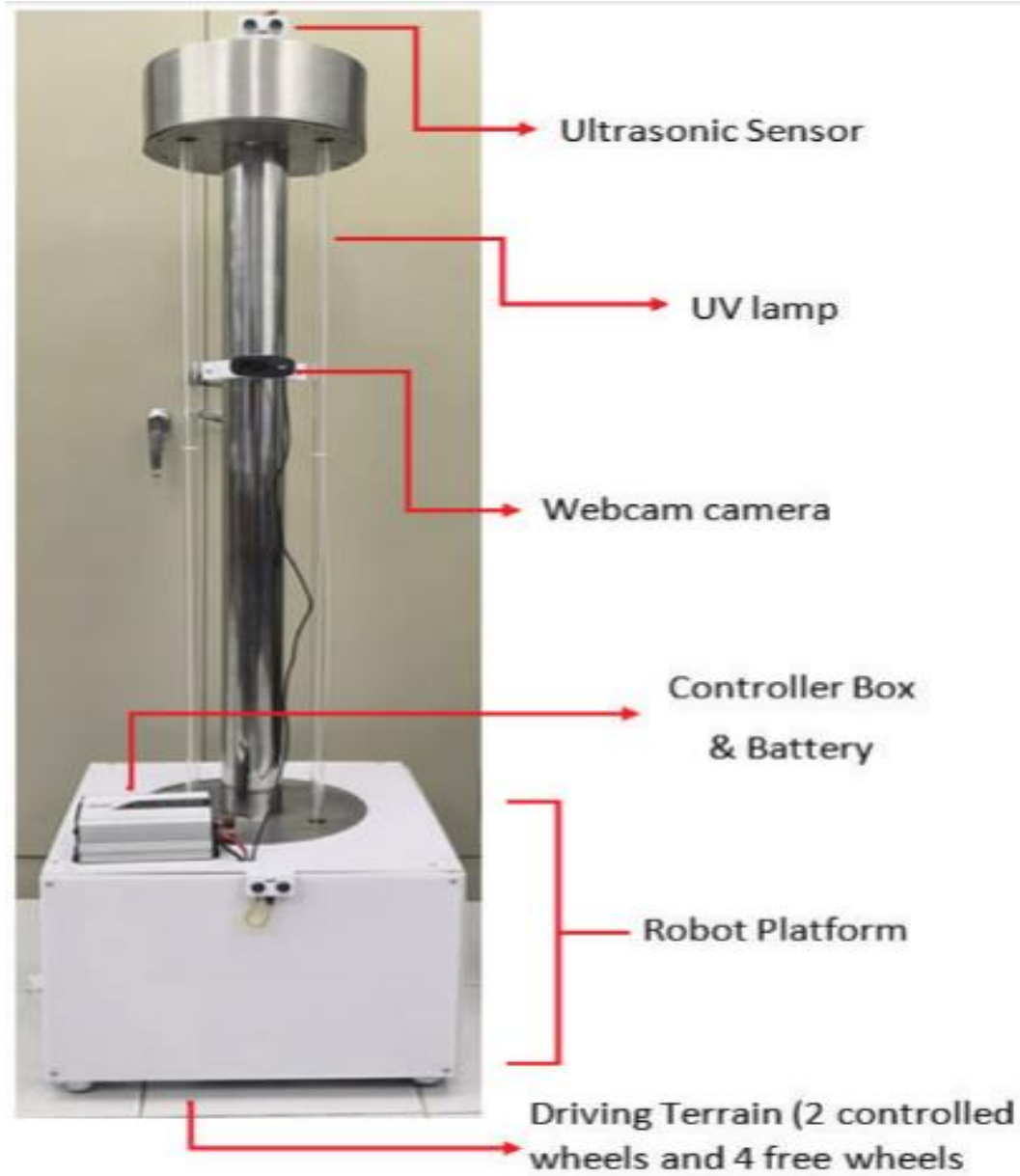

(b)

Figure 3: (a)The prototype robotics ultraviolet-Light System, (b) UV sterilisation robot (Chanprakon et al. 2019).

where $B_{262}^{0}$ and $B_{262}$ is the solution absorbance of actinometer which occur before and after being irradiated at $262 \mathrm{~nm}, \frac{\log _{e}\left(\frac{B_{262}^{0}}{B_{262}}\right)}{\tau}$ (per second), is the gradient linear trendline of the curve of $\log _{e}\left(\frac{B_{262}^{0}}{B_{262}}\right)$ with time, $\tau$ is time measured in seconds, $N$ is the photo emitted energy at 275 nanometers $i s 7.23 \exp (19)$, the result gives the energy per mol of the photon $\left(\mathrm{J} E^{-1}\right)$ when multiplied by Avogadro's number; $\exists_{262}$ is $8 \times$ $10^{3}$ measured in (per mole, per $\mathrm{cm}$ ) depicts the molar annihilation uridine coefficient at $262 \mathrm{~nm}$ (Cataldo 2017) and $\varphi$ is the quantum yield (number of events/number of the photon absorbed) of uridine photohydration which is $0.016\left(\mathrm{~mol} E^{-1}\right)(\mathrm{Kuhn}, 2004)$ and 2.303 is $\log _{\mathrm{e}} 10$. The model assumed that throughout the ultraviolet exposures the quantum yield remains constant.

Having determined the ultraviolet intensity $\zeta$, the ultraviolet fluence $(\psi)$ measured in $\left(\mu \mathrm{J}_{\mathrm{cm}}{ }^{-2}\right)$ irradiated over each exposure time can be calculated using Eq. (4), taking into account changes in the effective dose caused by impurities which reduce the effective dose to the organism:

$\psi=\zeta \times \frac{1-10^{-B 275 \times r}}{B_{275} \times r \times \ln (10)} \times \tau=\zeta \tau \quad\left(\mu \mathrm{J} \mathrm{cm}^{-2}\right)$

where $r$ represents the radius of the reactor bowl measured in centimeter

The Power $\chi(\mu \mathrm{W})$, of the discharged ultraviolet Clamp, determines the dose received by surface unity at a given distance $v$ in centimeter from the sanitizer which was Eq. (5) (Owens et al, 2005).

$$
\psi=\frac{\chi \tau}{2 \pi \lambda v}\left(\mu \mathrm{Jcm}^{-2}\right)
$$

where $\lambda$ is measured in centimeter and $\tau$ time in seconds were respectively the length of the lamp and the exposure time, so the exposure time can be estimated according to Eq. (6): 


\section{Mathematical Model of the Robotic device}

This research work focused on robotics ultraviolent light systems due to the effect of ultraviolet light on human health if not used with care. With this prototype ultraviolet light, human direct involvement in the sanitization of environs will no longer be there. The only thing needed is to notify individuals when and where the sanitizations will take place and at the same time the duration of the exercise by pasting a notice there. It was expected that the robotic device was built with four ultraviolet light lamps around the robotic device for the purification exercise hence the device modeling will consist of the physical behavior of the system, based on cinematic and kinematic energy.

The body movement without taking note of the force/torque that was pressing on its body or causing the movement is regarded as kinematics to the robotic mechanism. The procedure of plotting a robot manipulator from Joint-space to Cartesian-space (sometimes known as task space) can be regarded as frontward kinematics. This action can easily be determined by the transformation of the data generated from the kinematic of the robotic device's joint-space to the Cartesian space. The coordinate of a robot end-sensory conversion matrix to the base frame generally can be obtained by the use of Hartenberg Denavit's s method (Jazar, 2010). At this juncture, it is worthy to note that the D-H method is concerned with the transformation amongst two end-to-end coordinate settings. Conventionally, when the D-H method is applied, the synchronize settings $\varpi_{\mathrm{i}}$ is converted from the synchronize settings to $\varpi_{i-1}$ by the homogenous transformation matrix ${ }^{i-1} \lambda_{i}$ (Wee, 2014);

$$
{ }^{i-1} \lambda_{i}=\left[\begin{array}{cc}
{ }^{i-1} \eta_{i} & { }^{i-1} \nu_{i} \\
0 & 1
\end{array}\right]=\left[\begin{array}{cccc}
\cos \phi_{i} & -\sin \phi_{i} \cos \phi_{i} & \sin \phi_{i} \sin \vartheta_{i} & \vartheta_{i} \cos \phi_{i} \\
\sin \phi_{i} & \cos \phi_{i} \cos \vartheta_{i} & -\cos \phi i \sin \vartheta_{i} & \vartheta_{i} \sin \phi_{i} \\
0 & \sin \vartheta_{i} & \cos \vartheta_{i} & v_{i} \\
0 & 0 & 0 & 1
\end{array}\right]
$$

222

223

where ${ }^{i-1} \eta_{i}$ represent a 3 x 3 matrix portraying spinning and ${ }^{i-1} v_{i}$ was a $3 \times 1$ vector depicting to and fro motion. Also, the inverse transformation equation to convert the synchronize setting $\varpi_{i}\left(a_{i}, b_{i}, c_{i}\right)$ to synchronize setting $\varpi_{i_{-1}}\left(a_{i-1}, b_{i-1}, c_{i-1}\right)$ was

$$
\left[\begin{array}{c}
a_{i-1} \\
b_{i-1} \\
c_{i-1} \\
1
\end{array}\right]=i-1 \lambda i\left[\begin{array}{c}
a_{i} \\
b_{i} \\
c_{i} \\
1
\end{array}\right]
$$

Solving the frontward location kinematics of a joint coordinate from the standpoint of the base frame can easily be achieved using a combined transformation matrix as depicted in Eq. (9)

$$
\begin{aligned}
{ }^{0} \lambda_{\mathrm{n}} & ={ }^{\mathrm{o}} \lambda_{1}\left(\partial_{1}\right){ }^{1} \lambda_{2}\left(\partial_{2}\right){ }^{2} \lambda_{3}\left(\partial_{3}\right) \ldots . . . .{ }^{\mathrm{n}-1} \lambda_{\mathrm{n}}\left(\partial_{\mathrm{n}}\right) \\
& =\left[\begin{array}{llll}
z_{11} & z_{12} & z_{13} & z_{14} \\
z_{21} & z_{22} & z_{23} & z_{24} \\
z_{31} & z_{32} & z_{33} & z_{34} \\
z_{41} & z_{42} & z_{43} & z_{44}
\end{array}\right]
\end{aligned}
$$

For $z_{i j}=z_{j i}(\partial \sigma), \quad \sigma=1,2 \ldots \mathrm{n}$

where $\mathrm{n}$ denotes the degree of freedom.

The rotational matrix for the three a-b-c axes were as shown in Eq. (10) - (12).

$$
\begin{aligned}
\eta_{a}(\phi)= & {\left[\begin{array}{ccc}
1 & 0 & 0 \\
0 & \cos \phi & -\sin \phi \\
0 & \sin \phi & \cos \phi
\end{array}\right] } \\
& \eta_{b}(\phi)=\left[\begin{array}{ccc}
\cos \phi & 0 & \sin \phi \\
0 & 1 & 0 \\
-\sin \phi & 0 & \cos \phi
\end{array}\right] \\
& \eta_{c}(\phi)=\left[\begin{array}{ccc}
\cos \phi & -\sin \phi & 0 \\
\sin \phi & \cos \phi & 0 \\
0 & 0 & 1
\end{array}\right]
\end{aligned}
$$




\section{Discussion}

The prototype robotic device comprises four ultraviolet lamps which were fixed centrally in the body of the machine device with one lamp on top with numerous sensors. The robotic device has to master its environment via a mapping process. For this action to take place, light detection and ranging sensors of robotics system played a major role in it surveying the environs and develops an appropriate digital map. Through the help of inbuilt affections in the device, the robot responds impulsively to any stimuli within its environs quickly on its own. Whenever the device is in operation if it senses the presence of any human being via one of the sensors, an inbuilt alarm will be triggered. The alarm is the form of a recorded voice which goes thus, "move out from here, it is unsafe for you" if such a person couldn't move out within 10 nanoseconds, the sensor then triggered shutdown switch of the ultraviolet light automatically. Normally, 15 to 25 minutes were required to sanitize the award/apartment. With the wavelength of 254-nanometer light, microbes were incapacitated to the tune of 99.99\% in few a minutes when the robot ultraviolet light discharges $20 \mathrm{Jm}^{-2} \mathrm{~s}^{-1}$ (Magda et al, 2021). Hence, the involvement of this prototype is better than human cleansing because it will eradicate the hazard that can affect human health. Therefore, applying robotic ultraviolet light minimizes the spread of covid-19 like a wildfire which is the global pandemic drowning the entire world to a halt.

\section{Conclusion.}

Necessity is the mother of invention, the inception COVID-19 pandemic enhanced innovation on all spheres of life; both public, societal, and medical alike. Deploying robotic devices for decontamination of hospital sensitive equipment as well as its environs and other related surroundings has a greater potential in the future. If appropriately utilized more especially in the health sector, the Robotic ultraviolet light will assist in reducing the health hazards of using improperly sterilized equipment.

\section{Authors' Contributions}

T.O Araoye and D.B Nnadi works on design and analysis of the robotic system, Validation of the design was done by D.A Vincent and S.V Egoigwe. Writing Review and Editing was done by T.O Araoye and D.B Nnadi, Project Administration was done by S.V Egoigwe and D.A Vincent, Formal Analysis was done by D.B Nnadi and T.O Araoye,. Writing -original draft preparation was done by D.B Nnadi

All authors carried out the analysis and contributed to writing of the paper.

\section{Acknowledgment}

The authors would like to appreciate Energy and Sustainable Research Group (ESRG) for their technical support.

\section{Funding}

This research received no external funding

\section{Compliance with ethical standards}

Competing interests: The authors declare no conflict of interest

Ethical approval: Not applicable

Consent to participate: The authors have consent to participate

Consent to publish: The authors have consent to publish.

Availability of data and materials: Not applicable

\section{References}

ASHRAE (2019) Ultraviolet Air and Surface Treatment, ASHRAE Handbook - HVAC Applications (SI), Pp 61.

Balasubramanian, D. (2000).Ultraviolet radiation and cataract. J. Ocul. Pharmacol. Ter. 16(3), 285-97

Bai, Y. et al. (2020). Presumed asymptomatic carrier transmission of covid-19. JAMA,

Budowsky, E. I. et al. (1981). Principles of selective inactivation of the viral genome. I. UV-induced inactivation of influenza virus. Arch. Virol. 68(3-4), 239-47. 
Cataldo, F. Uridine as Photochemical Actinometer: (2017) Application to UV-LED Reactors. Eur. Chem. Bull. 6, 405-409.

Chanprakon, P.; Sae-Oung, T.; Treebupachatsakul, T.; Hannanta-Anan, P.; Piyawattanametha, W. (2019). An Ultra-violet sterilization robot for disinfection. In Proceedings of the 2019 th International Conference on Engineering, Applied Sciences and Technology (ICEAST), Luang Prabang, Laos, 2-5 ; pp. 1-4

Chick H,( 1908) An investigation of the laws of disinfection. JHyg 8: 092-158.

Darnella MER, Subbaraob K, Feinstonea SM, Taylora DR (2004) Inactivation of the coronavirus that induces severe acute respiratory syndrome, SARS-CoV. J Virol Methods 121:85-91. https://doi.org/ 10.1016/j.jviromet.2004.06.006

Derraik, J. G. B, Anderson, W. A, Connelly, E. A \& Anderson, Y. C. (2020). Rapid Review of SARS-CoV-1 and SARS-CoV-2 Viability, Susceptibility to Treatment, and the Disinfection and Reuse of PPE, Particularly Filtering Facepiece Respirators, Int. J. Environ. Res. Public Health, 17, (6117), 1-33, doi:10.3390/ijerph17176117.

Farhad Memarzadeh, Ph.D., PE, a Russell N. Olmsted, MPH, CIC,b and Judene M. Bartley, MS, MPH, CICc Bethesda, Maryland; Ann Arbor, Michigan; and Beverly Hills, Michigan, (2010)."Applications of ultraviolet germicidal irradiation disinfection in health care facilities: Effective adjunct, but not stand-alone technology", American Journal of Infection Control pp. S13- S24. doi:10.1016/j.ajic. 2010.04.208

Hebling M., Hones K., Vatter, P \& Lingenfelder C. (2020). Ultraviolet Irradiation Doses for Coronavirus Inactivation - Review and Analysis of Coronavirus Photoinactivation Studies, GMS Hygiene, and Infection Control, 15, I-8

Heilingloh, C. S., Aufderhorst, U. W., Schipper, L., Dittmer, U., Witzke, O., Yang, D., Zheng, X., Sutter, K., Trilling, M., Steinmann, E \& Krawczyk, A. (2020). Susceptibility of SARS-CoV-2 to UV irradiation, American Journal of Infection Control, 48 (10) 1273-1275. https://doi.org/10.1016/j.ajic.2020.07.031.

IESNA. (2000). Lighting Handbook: Reference \& Application IESNA HB-9-2000. New York: Illumination Engineering Society of North America.

Jazar R. N., Theory of Applied: Robotics, Kinematics, Dynamics and control, Book Springer 2010

Kamiko N, Ohgaki S, Rna coliphage (1989) as a bioindicator of the ultraviolet disinfection efficiency. Waf SciTech 21:227-231,

King, Anthony "An uncommon cold". New Scientist (1971). 246 (3280): 32- 10.1016/S02624079(20)308629. ISSN 02624079.35. DOI: PMC 7252012. PMID 32501321 (2020-05-02).

Kitagawa, H, Nomura, T, Nazmul, T, Omori, K, Shigemoto, T \& Ohge, H. (2020). Effectiveness of $222 \mathrm{~nm}$ Ultraviolet Light ON DISINFECTING Sars-Cov-2 Surface Contamination, American Journal of Infection Control, Doi: 10.1016/j.ajic.2020.08.022.

Kowalski W. (2009) Ultraviolet Germicidal Irradiation Handbook. UVGI for Air and Surface Disinfection, New York: Springer.

Ko G, First MW (2000) Burge HA, Influence of relative humidity on particle size and UV sensitivity of Serratia marcescens and Mycobacterium Bovis BCG aerosols. Tuber Lung Dis 80:217-228. https://doi.org/10.1054/tuld.2000.0249

Kuhn, H.; Braslavsky, S.; Schmidt, E. (2004) Chemical actinometry (IUPAC technical report). Pure Appl. Chem. 76, 2105-2146.

Laboratory testing of human suspected cases of novel coronavirus ( $\mathrm{nCoV}$ ) infection. Interim guidance, 10 January 2020" (PDF). Archived (PDF) from the original on 2020-01-20. Retrieved 2021-01-14.

Lucas, J. What is Ultraviolet Light? (2017). Retrieved online from livescience.com 04/02/2021.

Luckiesh M. 1946. Applications of Germicidal, Erythemal, and Infrared Energy. New York: D. Van Nostrand Co.

Magda Diab-El Schahawi, Walter Zingg, Margreet Vos, Hilary Humphreys, Lorena Lopez-Cerero, Astrid Fueszl, Jean Ralph Zahar (2021). Ultraviolet disinfection robots to improve hospital cleaning: Real promise or just a gimmick. Antimicrobial Resistance \& Infection Control

Mcdevitt JJ, Rudnick SN, Radanovich L, (2012). Aerosol susceptibility of influenza virus to UV-C light. Appl Environ Microbiol 78:1666-1669. https://doi.org/10.1128/AEM.06960-11. 
Moez Guettari \& Ines Gharbi \& Samir Hamza, (2020). UVC disinfection robot, Environmental Science and Pollution Research https://doi.org/10.1007/s11356-020-11184-2, Springer-Verlag GmbH Germany, part of Springer Nature.

Mojarad N, Khalili Z, Aalaei S (2017) A Comparison of the efficacy of mechanical, chemical, and microwave radiation methods in disinfecting complete dentures. Dent Res J (Isfahan) 14:131-136;

Naunovic, Z., Lim, S. \& Blatchley, E. R. III. (2008) Investigation of microbial inactivation efficiency of a UV disinfection system employing an excimer lamp. Water Res. 42(19), 4838-46.

Narita, K., Asano, K., Morimoto, Y., Igarashi, T., Hamblin, M., Dai, T \& Nakane, A. (2018). Disinfection and Healing Effect of 222NM UVC light on Methicillin-Resistant Staphylococcus Aureus Infection in Mouse $\begin{array}{lllll}\text { Wounds, } \quad \text { P. Photochemistry, } & \text { and }\end{array}$ https://doi.org/10.1016/j.jphotobiol.2017.10.030.

Novel Coronavirus 2019, Wuhan, China. www.cdc.gov (CDC). 2020-01-23. Archived from the original on 2020-01-20. Retrieved 07-02-2021.

Novel Coronavirus infection (Wuhan, China) (2019): Outbreak update". Canada.ca. Retrieved 07-02-2021.

Otto C, Zahn S, Rost F, Zahn P, Jaros D, Rohm H (2011) Physical methods for cleaning and disinfection of surfaces. Food Eng Rev 3:171-188. https://doi.org/10.1007/s12393-011-9038-4;

Owens MU, Deal DR, Shoemaker MO, Knudson GB, Janet E, Deal JL (2005) High-dose ultraviolet C light inactivates spores of Bacillus subtilis var. niger and Bacillus anthracis Sterne on non-reflective surfaces. Appl Biosaf 10:240-247. https://doi.org/10.1177/153567600501000406

Setlow, R. B. et al. (1993). Wavelengths effective in induction of malignant melanoma. Proc. Natl Acad. Sci. USA 90(14), 6666-70.

Trevisan, A. et al. (2006). Unusual high exposure to ultraviolet-C radiation. Photochem. Photobiol. 82(4), 10779.

UVC LED disinfection. (2013). Green Island, NY: Crystal IS.

Van Doremalen, N. et al. (2020). Aerosol and surface stability of sars-cov-2 as compared with sars-cov-1. N. Engl. J. Med

Wee Teck Chew, Design and Control of a Humanoid Robot, Thesis submitted in partial fulfillment of the requirements for the degree of Doctor of Philosophy, in the subject of Robotics and Control Systems Control and Power Research Group, Department of Electrical and Electronic Engineering Imperial College London, June 2014.

World Health Organization. Coronavirus Disease (Covid-19) situation reports, Retrieved online from https//www.who.int/emergencies/diseases/novel-coronavirus-2019/situation-reports. 10/02/2021.

Zafna, S. et al.(2012) Accidental exposure to UV radiation produced by germicidal lamp: case report and risk assessment. Photochem. Photobiol. 88(4), 1001-4. 